\title{
The Self-Assessment Perceived Global Distress Scale-Reliability and Construct Validity
}

\author{
-Perceived Global Distress Scale
}

\author{
Bo Ivarsson ${ }^{1}$, Leif Lindström ${ }^{2}$, Ulf Malm ${ }^{3}$, Torsten Norlander ${ }^{1}$ \\ ${ }^{1}$ Department of Psychology, Karlstad University, Karlstad, Sweden; \\ ${ }^{2}$ Department of Neuroscience, Psychiatry, Uppsala University, Uppsala, Sweden; \\ ${ }^{3}$ Institute for clinical neuropsychiatry, Sahlgrenska University Hospital, Gothenburg, Sweden. \\ Email: bo.ivarsson@bornet.net \\ Received March $8^{\text {th }}, 2011$; revised April 16 ${ }^{\text {th }}, 2011$; accepted May $17^{\text {th }}, 2011$.
}

\begin{abstract}
Objective: the aim was to study psychometric properties of the Perceived Global Distress Scale (PGD) for people with severe mental illness, mainly with schizophrenia disorders. Methods: PGD is a Visual Analogue Scale included in "The Quality Star", a minimal platform for clinical follow-up and efficiency documentation of mental health services in eight dimensions used in Sweden. Naturalistic data was used. Validating instruments included Quality of Life-100, Symptom Check List-90, Consumer Satisfaction Rating Scale - self-rating version, Manchester Short Assessment of Quality of Life (MANSA), Global Quality of Life scale, Care Burden Scale for Relatives, Perceived Global Burden, Brief Psychiatric Rating Scale (BPRS), Side Effect Rating Scale (SERS), and Global Assessment of Functioning (GAF) - the split-GAF version. Concurrent validity with corresponding item in MANSA was explored. Test-retest reliability of the GQL was examined. Results: the content validity was clarified by associations with validating measures from several contexts in three studies, supporting construct validity. Concurrent validity with the last item MANSA, "How satisfied are you with your mental health?", was demonstrated. Test-retest reliability was indicated. Conclusion: the Perceived Global Distress Scale (PGD) was shown to have acceptable psychometric properties and valid for serious mental ill persons with schizophrenia disorders. Its use as an easy-to-use instrument for the screening of perceived global mental distress was supported.
\end{abstract}

Keywords: Schizophrenia, Severe Mental Illness, Distress, Visual Analogue Scale, Perceived Global Distress Scale

\section{Introduction}

To support continuous improvement for the quality of care, a concept was developed for regular (i.e., at least yearly) follow-up together with the user and his or her next of kin. The concept called "The Quality Star" (Erdner \& Ivarsson, 2002; Ivarsson, Erdner, \& Malm, 2006), aimed to be a minimal platform for the follow-up of psychiatric care in a multi-dimenonal, holistic perspective using simple measures of generic nature. Instruments should be handy in clinical praxis. They should fill the function to be a point of departure for a dialogue with users with an under-lying question "Where do we stand now and how do we improve?" The aspects chosen for regular review include professional ratings of present syndrome severity and psychosocial functioning as well as user ratings of perceived complaints, satisfaction with services, subjective quality of life, and also the burden to an important relative. The inclusion of patients' and relatives' subjective measures was strongly motivated by the desire to secure that user perspective is in focus. With this perspective the choice of global instruments was made, illustrated in Figure 1.

* The research plan has been evaluated and approved by the Regional Ethical Vetting Board in Uppsala and the study followed the ethical standards of the World Medical Association declaration of Helsinki concerning Ethical Principles of Medical Research Involving Human Subjects.

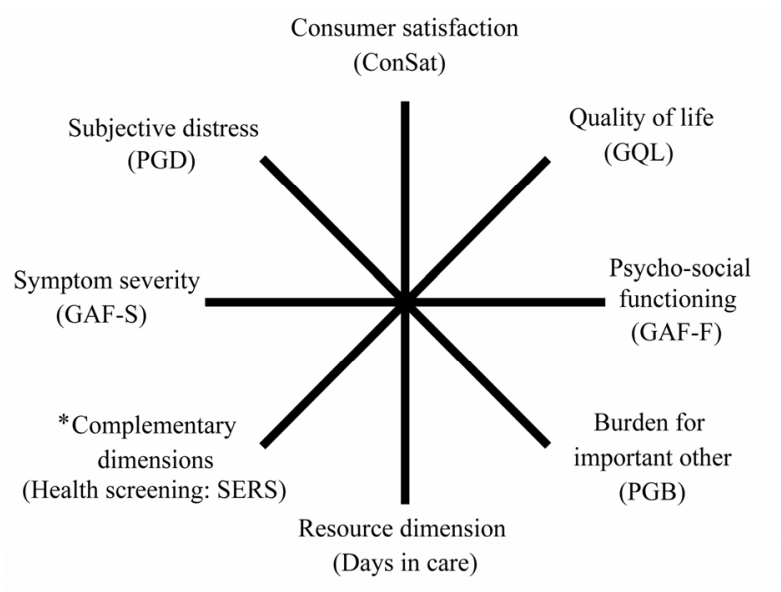

*This axis is intended for specific extra measures when suitable. Health screening (SERS is recommended for all patients.

For psychosis groups, Remission index (RS-S) is now being introduced.

Figure 1.

Graphic representation of global instruments in "The Quality Star" concept. Measures used for each dimension in parentheses. In addition to chosen quality dimensions, a representation of resource use is included in the bottom of the "star" by number of "days in care", later to be specified by national treatment content codes. 
It was understood that more detailed instruments have to be used in addition to the global measures in clinical work and research, in varying degree depending upon focus and tasks. However, the basic, simple instruments desired should be good enough to be useful in benchmarking between the clinical centers participating in the Quality Star Network.

Regarding global mental distress or complaints, a minimal instrument for rating the subjective, perceived dimension of the phenomenon was sought. The network chose to use a single visual analogue scale (Bech, 1993; Everitt \& Wykes, 1999), the Perceived Global Distress Scale (PGD), constructed for the purpose by the network (GGG-group, 2009). It is an adaptation for stand-alone use of the last item "How satisfied are you with your mental health?" in Manchester Short Assessment of Quality of Life (MANSA) (Priebe, Huxley, Knight, \& Evans, 1999). However, the focus was narrowed by changing the introductory question to "How much have you been bothered by your psychiatric problems during the last month?". The phenomenon sought to capture by the scale is the degree of feeling mentally distressed and/or having complaints regarding mental health, irrespective of how the respondent arrived to an opinion. Degrees of positive mental health are not focused, which is a difference to the MANSA. Thus, the PGD scale assumes that most psychiatric patients experience degrees of mental health distress, and if not, the scale does not give room for expressing degrees of satisfaction with mental health. The intention with this restriction was to guide the respondent to focus on the issue if mental health problems existed at all. In this sense, the PGD is intended to support problem identification in the mental health area together with the patient. A following dialogue should clarify the precise nature of the problems that the patient experiences. This was deemed advantageous compared to using any of numerous available short form instruments with similar aims, for instance the WHO Self Reporting Questionnaire 20 (Harpham et al., 2003), General Health Questionnaire (Goldberg \& Williams, 1988), Kessler Psychological Distress Scale (Andrews \& Slade, 2001), Psycho-Social Well-Being Scale (O'Hare et al., 2003). Though they are well-proven to detect mental health problems, the more open question alternative based on the MANSA item was preferred. More syndrome directed self-assessments, for instance Hopkins Symptom Check List (Derogatis, 2000) would not be alternatives because of the inclination to professional concepts, being syndrome oriented or because too lengthy.

The Quality Star Concept has been adopted by a number of services in Sweden. Though the measures used have generally been seen as useful in the clinic, there has also been criticism that some of the instruments have not been properly investigated regarding their psychometric properties. The initial assumption that the new single item scales, like the PGB, derived from established item in MANSA with relatively small adjustments did not necessarily need thorough investigations before being used was questioned. Therefore several studies have recently been launched dedicated to investigate the validity and reliability of instruments included in the Quality Star Test Battery, as the material available in the National Network Database now permits basic studies. The aim of the present study was to investigate the psychometric properties of the Perceived Global Distress Scale (PGD) for seriously mentally ill (SMI) persons with predominantly schizophrenia disorders.

\section{Methods}

\section{Participants}

Participants in this study were 1670 patients, 937 men and 733 women, where the Quality Star has been used on one or more occasions during a ten year period at psychiatric centers in 13 areas throughout Sweden, and where data was complete regarding professional and patient instruments. At the first recorded use, their mean age was 43.77 years $(S D=12.15)$. The majority, $87.87 \%$, had schizophrenia spectrum disorders (ICD codes F20-F29). The remaining patients had representations in particular from depressive and anxiety states (F30-F49). They were, by large, SMI patients in long-term treatment and support and rehabilitation schemes. Their reported mean duration of illness was in the order of 17 years (SD about 11).

Some of the analyses were done on sub-samples with optional use of instruments. The sub-samples were judged to be similar enough regarding age, sex and diagnosis composition to allow their uses in this study. Details are mentioned at the end of the respective instruments presentations below.

\section{Instruments}

Perceived Global Distress Scale (PGD). The instrument is a visual analogue scale (GGG-group, 2009). The introductory question has the wording "How much have you been bothered by your psychiatric problems during the last month?" and the anchor-points of the VAS line is marked "I have not experienced any psychiatric problems at all" and "My psychiatric problems have troubled me extremely much". The scale is a 10 $\mathrm{cm}$ line, thus giving a scale $0-100 \mathrm{~mm}$. Rating 0 represents the worst possible situation and 100 represents no problems. Presently, only two validation studies are available on limited patient materials by Bergman (2003) and Söderberg (2007). Healthy adult population data for the PGD, was studied in a separate work (Ivarsson, Andersson, Malmström, Carlsson, \& Johansson, 2010) and found to be mean $89.55(S D=19.18)$ which may be compared with the mean value for patients in the present study $(M=62.74, S D=27.90)$.

Quality of Life-100 (QOL-100). The Quality of Life-100 scale was constructed primarily to support working together with patients regarding problem finding and solving (Skantze, Malm, Dencker, May, \& Corrigan, 1992). The inventory contains 100 items in 14 dimensions (subscales) including Housing, Household and Self-Care, Leisure, Housing Environment, Community Services, Knowledge and Education, Contacts, Physical Health, Mental Health, Work, Finances/Savings, Inner Experience, Dependence, and anything else unsatisfactory. The number of items in each domain differs. The patient is instructed to encircle items that are perceived as unsatisfactory in life at the moment. This gives the value 1 and no mark gives the value 0 . The values on the subscales are calculated through simple averaging the scores and expressing the percentage of items rated unsatisfactory. Total score is obtained by expressing the percentage of total number of items encircled. Test-retest reliability was found good ( $r=0.88$ over 7 - 10 days). Correlations between subscales and total sum were between $r=0.48$ to 0.87 . The total sum is also considered as a quality of life measure (Skantze \& Malm, 1994). The mean value for QOL-100 in the present study was $13.51(S D=11.42)$ for those patients $(\mathrm{N}$ $=179$ ) who used this optional instrument. Their background 
characteristics were close to the total subset values.

Symptom Check List-90 (SCL90). The SCL-90 is a psychiatric self-report inventory with 90 items scored on a fivepoint Likert Scale of Distress with anchor points 0: none; 1: a little bit; 2: moderately; 3 :quite a bit; and 4: extremely, indicating the rate of occurrence of the symptom during the last week (Derogatis, Lipman, \& Covi, 1973). The SCL-90 is well-suited for measuring general mental health and changes in symptoms (Bech, et al., 1993; Derogatis, 1994). The SCL-90 has been used as a central outcome measure in numerous clinical trials, as an outcome measure, as a measure of mental status, and as a screening instrument. It has been shown to have a good reliability with high internal consistency. It discriminates patients from normal controls well and there is support for its validity as a measure of general symptom severity, but there less support for its suggested dimensionality and the nine subscales should thus be treated with some caution. (Fridell, Cesarec, Johansson, \& Malling Andersen, 2002; Holi, 2003). Validation of Swedish versions in use, have been done by Fridell et al. (2002). The mean value for SCL-90 in the present study was $1.11(S D=0.77)$. This instrument, for optional use, was used in part of the material $(\mathrm{N}=45)$. Background characteristics were similar to the total subset values, though somewhat younger (mean 35 years), with shorter illness duration (mean $=11.72$ years), and more homogenous regarding diagnosis (98\% schizophrenia).

Consumer Satisfaction Rating Scale-Self-Rating Version (ConSat-P). This self rating scale has questions in 6 process quality domains (availability, atmosphere, treatment modalities, information, drug treatment and psychosocial interventions) and two out-come related domains (usefulness of treatment/care and general well-being) (GGG-group, 2009). The ConSat-P scale has been shown to have acceptable psychometric proper- ties including acceptable internal consistency. Its use has been validated for schizophrenia spectrum disorders as well as for affective, anxiety and substance abuse syndromes (Ivarsson \& Malm, 2007). In this study, the first 11 items was used as the 12th item, regarding general well-being, was used as a specific instrument (the GQL - see below). These items were rated on a seven point scale with the format in principle +3 full satisfaction, +2 satisfied but with minor dissatisfaction, +1 More satisfaction than dissatisfaction, 0 equally satisfaction/dissatisfaction or indecisive, -1 to -3 formulated in a reciprocal fashion. The summary score thus, ranges from $-33-+33$. The Mean Value for patients in the present study was $16.60(S D=9.78)$.

Manchester Short Assessment of Quality of Life (MANSA). The MANSA (Priebe et al.,1999) contains 12 subjective quality of life items (Life as a whole, Work satisfaction, Economy, Satisfaction with friends, Leisure activities, Housing, Personal safety, Satisfied with people you live with/living alone, Sex life satisfaction, Satisfaction with family relations, Satisfaction with physical health, Satisfaction with mental health). Items are rated on a 7-point rating scale $(1=$ Couldn't be worse, $7=$ Couldn't be better). Cronbach's alpha for the satisfaction ratings was 0.74 . The mean score of all satisfaction ratings was used as the total measure for subjective quality of life (MANSA-tot). The MANSA was validated in Sweden for serious mental ill (SMI) persons by Björkman and Svensson (Björkman \& Svensson, 2005) in regard to social network aspects and to beliefs of devaluation/discrimination. They also found internal consistency adequate (Cronbach's alpha $=0.81$ ).
The mean value for MANSA-tot in the present study was 4.51 $(S D=0.95)$. This instrument was optionally used at some places $(\mathrm{N}=27)$. Background characteristics were similar to the total subset values; though males were more common (male/ female $66.7 / 33.3 \%$ ) and duration of illness somewhat longer (mean 20.6 years).

Global Quality of Life Scale (GQL). The instrument is a Visual Analogue Scale (GGG-group, 2009). The introductory question has the wording" How do you find your life situation right now?" and the anchor-points of the VAS line are marked "Best possible life situation" and "Worst possible life situation". The scale is a $10 \mathrm{~cm}$ line, thus giving a scale $0-100 \mathrm{~mm}$. Rating 0 represents the worst possible quality of life and 100 the best possible. The GQL has been found valid for serious mental ill persons with acceptable psychometric properties (Ivarsson, Malm, Lindström, \& Norlander, 2010). Test-retest reliability was found satisfactory. Concurrent validity with the initial item of life satisfaction scale of MANSA, "How satisfied are you with your life as a whole today", was good ( $r=0.85$ and $r h o=$ 0.86 ). Content validity was clarified by associations with a number of validating measures. The Mean Value for GQL in the present study was $60.39(S D=25.05)$.

Care Burden Scale for Relatives (CBS-R). This comprehensive scale was developed to describe the burden of relatives and its change after interventions (Bergmark, Durling, Boström, $\&$ Wistedt, 1990). Six areas are covered with a total of 92 items. Items are constructed as 4-point scales using anchors of 1: No; 2: Sometimes; 3: Often and 4: All the time. The six areas are: emotional burden, day-to-day aspects of burden, effects on health, work, and siblings, and, finally, views of medication and psychiatry. Psychometric properties of the CBS-R were studied by Hjärthag, Helldin, and Norlander ( 2008), who found internal consistency of the scale (Cronbach's alpha 0.96). Concurrent validity, tested by total score correlations with the Clinical Global Impression scale, GAF, Camberwell Assessement of Needs, was plausible ( $r s=.28$ to .44 ). Content validity was further clarified by step-wise regression of all CBR-S items using the PGB as criterion variable. The mean value for total CBS-R in the present study was $38.67(S D=44.32)$. This instrument for optional use was used at some places $(\mathrm{N}=49)$. The background characteristics for those participants were similar to the total subset values, though sex distribution was more equal (male/female 49/51\%) and duration of illness was shorter (mean 12.5).

Perceived Global Burden (PGB). This is a Visual Analogue Scale constructed in a similar way as the GQL (GGG-group, 2009). The introductory question has the wording "How big a burden have you experienced (felt) the last month due to your next of kin's psychiatric problems?" and the anchor-points of the VAS line are marked "No burdening feeling" and "The greatest possible feeling of burden". The scale is a $10 \mathrm{~cm}$ line, thus giving a scale $0-100 \mathrm{~mm}$. Rating 0 represents the worst possible situation and 100 no burden. The PGB manual [4] suggests that the respondent finally was asked what kind of burden made him/her put the cross at the actual place. The PGB has been validated in two studies (Erdner \& Eiman, 2003; Hjärthag et al., 2008) using the Care Burden Scale for Relatives (Bergmark et al., 1990) indicating strong associations to several subscales. The mean value for PGB in the present study was $66.76(S D=28.45)$. The instructions for use of this instrument 
includes a recommendation to use it with some caution and first consider if there is a present functioning contact with next of kins before using it. This, and the absence of relevant next of kins, resulted in less respondents $(\mathrm{N}=744)$. Their background characteristics were however similar to the total material.

Brief Psychiatric Rating Scale (BPRS). The 24 item BPRS, version 4.0 was constructed to follow psychotic and affective symptoms in serious mentally ill persons (Ventura et al., 1993).

Ratings are based on semi-structured interview (14 items) and observations (10 items). A detailed manual contains interview questions, symptom definitions and specific anchor points for the $1-7$ rating levels. The use required training, and with trained raters good inter-rater reliability was reported (ICC in the range of 0.8) (Ventura, Lukoff, Nuechterlein, Subotnik, \& Gilbert, 1995). The mean value for BPRS in the present study was $39.00(S D=13.23)$. Background characteristics for those patients where this optional instrument was used $(\mathrm{N}=124)$ were similar to the total subset values, except diagnosis was more homogenous (96.6\% schizophrenia).

Health Screening, Using the Side Effect Rating Scale (SERS). The SER comprises in its first part an inventory of 48 symptoms (45 for women and 42 for men) with well-defined items and scale steps clustered into psychic, neurological, autonomic and other symptoms areas (Lingjaerde, Ahlfors, Bech, Dencker, \& Elgen, 1987). Although it was primarily constructed for monitoring side effects in drug treatment, its broad content allows it to be used as a screening devise for health problems, regardless if they are side effects, part of a parallel disorder or part of a psychiatric syndrome. The scoring pattern is: 1. Not present; 2. Possible presence or discrete; 3. Clearly present; 4. Prominent. Only this first part, the "health screening" is used in this study. In the second part of SERS a judgment was made if the symptom present is or is not a medication side effect, which was not important when, (as in this study), validation of the PGD is the aim. The summary index used consisted of the sum of ratings on all items, i.e. if no symptom was observed the sum is 45 or 42 for woman and men respectively. The rating in percentage of maximum possible rating for each sex is used for calculating a Sex Neutral Index (SERS Index, 0 - 100). The Mean Value for the SERS Index in the present study was $35.59(S D=7.73)$.

Global Assessment of Functioning (GAF). The instrument measures global mental health from the perspective of psychic, social, and functional ability (American Psychiatric Association, 2000). The scale has ten vignettes exemplifying symptom severity and psychosocial functioning to be used as reference in rating, each vignette representing successive 10-point intervals in the semi-quantifying in the total scale range $1-100$. Rating 1 represents the maximum dysfunction and 100 the best possible function. In each vignette, the first part exemplifies syndrome severity and the last part psycho-social functioning. GAF is a much used scale and its psychometric properties are documented in several studies, e.g. by Patterson \& Lee (1995), Söderberg (2007), Söderberg \& Tungström (2007), and Yamauchi, Ono, Baba, and Ikegami (2001). The split-GAF version is used, with separate ratings of symptom severity (GAF-S) and psychosocial functioning (GAF-F) (Pedersen, Hagtvet, \& Karterud, 2007). The mean value for GAF-S in the present study was $50.44(S D=11.96)$ and for GAF-F it was $50.53(S D$ $=11.39$ ).

\section{Design}

Content validity of the PGD scale for SMI patients was studied using a dataset from the Quality Star Database where Registration was completed for all patients and professional instruments $(\mathrm{N}=1670)$. In addition, ratings on the PGB done by important others were used when completed, as well as a smaller number of ratings on optional instruments. Correlations between PGD and the other instruments were analyzed. Since data usually did not meet the demands for normal distribution, neither regarding kurtosis nor skewness, non-parametric statistics were chosen for the analyses (Spearman's rho). In analyses using instruments that were not used for all patients in the subset, patient background data was studied regarding representativeness. The smaller number of patients available in some of the analyses was due to the naturalistic nature of the data, as services use the instruments when locally considered useful in the specific clinical situation only. Also, because of the study being based on naturalistic data, no formal test-retest study was staged. Instead, available patient data with three consecutive yearly ratings were analyzed to address the issue.

\section{Procedure}

Decision to participate in the Quality Star Network by the psychiatric departments include ethical considerations regarding clinical follow up by using data from routine care and quality systems. The data software was not delivered to any site unless such declaration was given. The personal were trained in use of the instruments following the manual (GGG-group, 2009). Instructions include that GPD, as well as the other subjective instruments, should be used in a most neutral situation as possible, for instance not directly after focus on topics that may influence the rating. Subjective instruments should not be used immediately following each other, for the same reason.

Participants were introduced to the Quality Star at routine visits by their Case Manager (CM) and given written information. Right to withdraw without further motivation, and right to get extracts from the data-base was part of the information. If they chose to participate, this is noted in the clinical case notes. The $\mathrm{CM}$ went through the instruments with the patient at one or two ordinary appointments with the primary purpose to review the situation, to further the document findings in the patient's record, and in the Quality Star data-base. The CM prepared the first contact by reviewing notes to enter background data regarding history and sociodemographic questions. Recommended order to use the instrument is to start with GQL and then ConSat-P. Next the CM turned to the question if the participant would be willing to let a next of kin or an "important other" tell if he/she is troubled by burden in order to-if so-discuss how the situation might be improved. Written information of the Quality Star Method and the instrument PGB is presented. The next instrument presented is the PGD, followed by the SERS. Finally, the $\mathrm{CM}$ presented his rating of the GAF.

Additional instruments used locally to penetrate further the areas covered by the global measures mentioned above, such as using the BPRS to expand information of symptom severity beyond GAF-symptom rating, were presented after the global measures. Concluding, a summary presentation (Figure 1) of all ratings was done and discussed with the user what needs were to be taken care of in the following review of the personal 
treatment plan. Entries to the local Quality Star software are transferred to the national data-base at intervals where participant identification was replaced by random identification.

\section{Results}

Correlations between the PGD scale and used validation instruments are reported in three sections: Correlations with other self-report instruments (part 1), instruments used by important others (part 2) and professionally used instruments (part 3). Finally, the analyses regarding test-retest properties of the PGD are reported (part 4). Note that negative correlations reported are due to construct differences where high scores in some instruments represent the positive situation and in others the most problematic situation. Thus, all correlations are showing various degrees of convergent validity. Distinct divergent results did not appear in the analyses, though significant low correlations may be indicative.

\section{Results Part 1-PGD Correlations with Other Self-Report Instruments}

Spearman's correlation between PGD and the quality of life inventory QLS-100 total sum was $r h o=-0.39$ and in about the same level with items covering perceived problems with Mental Health, Felling understood by others, Shopping, and Inner Harmony (See Table 1 for further details here and in the fol-lowing results). The correlation with the Total Index of the Self-Report Symptom Inventory SCL-90 was $r h o=-0.54$, and in the same order with indices for interpersonal difficulties and anxiety. Correlation with the Depression Index was stronger (rho $=-0.64)$. The correlation with the Consumer Satisfaction Scale ConSat-P total sum was low, though $r h o=0.27$ for one of the items (Perceived results of treatment). No significant correlation was found for the MANSA mean, but two of the items, "Mental health" and "Life as a whole" had stronger correlations $(r h o=0.59$ and $r h o=0.54)$. Similarly, the correlation with the Global Quality of Life Scale GQL was $r h o=0.55$.

\section{Results Part 2-PGD Correlations with Instruments Used by Important Others}

No significant correlation was found with the CBS-R total score, and most notable correlation was found with the item "Problem understanding what happens" ( $r h o=-0.28)$. Correlation with the Global Burden Scale PGB was $r h o=0.32$. For details see Table 1.

\section{Results part 3-PGD Correlations with Professional Instruments}

Correlations between PGD and the total scores of the two symptom rating scales BPRS and SERS were in the same order ( $r h o=-0.41$ and $r h o=-0.45$ respectively). Several items had similar or near similar correlations, as can be seen in Table 1. The symptom severity rating with GAF-S had lower correlation $(r h o=0.24)$

\section{Results Part 4-Clinical Test-Retest Reliability Properties}

As a measure for test-retest reliability of the PGD scale
Spearman's correlations between a 2nd and 3rd consecutive year ratings was studied for patients in the Quality Star Database, who had previous years, i.e. 1 st and $2^{\text {nd }}$ recorded year, rated PGD on a equal level, not exceeding $+/-9$ points between years. This was chosen as indicating a subjective near equal perception of distress the two years. As a control for that the mental situation for the patients were reasonably equal also for year's 2 and 3, the professional GAF-symptom ratings was used. For the analysis only patients that did not differ more than $+/-9$ points on the GAF-symptom scale was used, assuming that this professional judgment indicated that symptom severity was near equal both years for this subgroup. Patients having used the Quality Star Ratings for three consecutive years were numbering 404. This subgroup with stable meeting the inclusion criteria as described above consisted of 118 persons $(60$ men and, 58 women. aged mean 46.28 and mean duration of illness 19.34 years. Diagnosis was in $95.59 \%$ schizophrenia spectrum disorders, ICD codes F20-F29. Spearman correlation between year 2 and year 3 PGD ratings for this group was $r h o=$ $0.75(p<0.001)$.

\section{Discussion}

The main results in this validation study regarding the PGD scale were: 1) content validity was clarified by associations with a number of validating measures and strengthened by the fact that findings were based on multi-site data. The findings were also supportive for construct validity; 2) concurrent validity with the last item of life satisfaction scale MANSA, "How satisfied are you with your mental health", was demonstrated; 3) clinical test-retest reliability was indicated.

The findings regarding content validity were suggested valid for seriously mental ill (SMI) persons, mainly in the schizophrenia spectrum of diseases, in supportive and/or rehabilitation phases in a Swedish context, given the comparatively large, naturalistic material from more than 13 hospital organizations including about 60 specific units with various service objectives for SMI patients ranging from intensive treatment and rehabilitation to supportive programs. The concurrent validity of the PGD with the last item of MANSA was found reasonably good (Spearman's correlation rho $=0.59$ ), considering the differences in construction pointed out in the Instruments section.

Associations found considered supporting content validity are summarized in Table 1. Associations with features of depression and anxiety as well as perceptions of interpersonal aspects were indicated by notable correlations between participants' PGD ratings and ratings on the subjective SCL90 (rho's about 0.5 - 0.6). Correlations with QLS-100 sum and several items (rhos between $-0.36-0.39$ ) were also indicating that the respondents' interpretation of the PGD construct includes, apart from mental health, interpersonal as well as autonomy and satisfaction elements. There was also an association to the dynamics of improvement shown by correlation with the specific item in the satisfaction scale ConSat-P $(r h o=0.27)$. The strong association between the PGD rating and perception of mental health and a quality of life dimension were further underlined by correlations to the relevant MANSA items (rhos about 0.5 0.6 ) and total sum, along with regarding quality of life, the correlation to the Global Quality of Life Scale GQL (rho = 0.55). The inclusion of an interpersonal element in patients' 
Table 1.

Correlations between PGD scale and totals of validation instruments as well as most prominent indices/items of the respective instruments.

\begin{tabular}{|c|c|c|c|}
\hline & \multicolumn{3}{|c|}{ Perceived Global Distress scale } \\
\hline & Spearman's rho & $p$-values & $n$ \\
\hline \multicolumn{4}{|l|}{ Self-report instruments } \\
\hline \multicolumn{4}{|l|}{ QOL-100 } \\
\hline Total sum & -0.39 & $<0.001$ & \multirow{5}{*}{179} \\
\hline Mental health & -0.37 & $<0.001$ & \\
\hline Feeling understood by others & -0.37 & $<0.001$ & \\
\hline Shopping & -0.37 & $<0.001$ & \\
\hline Inner harmony & -0.36 & $<0.001$ & \\
\hline \multicolumn{4}{|l|}{ SCL90 } \\
\hline Total index & -0.54 & $<0.001$ & \multirow{4}{*}{45} \\
\hline Depression index & -0.64 & $<0.001$ & \\
\hline Interpersonal index & -0.51 & $<0.001$ & \\
\hline Anxiety index & -0.50 & $<0.001$ & \\
\hline \multicolumn{4}{|l|}{ ConSat-P } \\
\hline Total sum & 0.19 & $<0.001$ & \multirow[t]{2}{*}{1670} \\
\hline Item "Perceived result of treatment" & 0.27 & $<0.001$ & \\
\hline \multicolumn{4}{|l|}{ MANSA } \\
\hline MANSA mean & 0.35 & 0.077 & \multirow{3}{*}{27} \\
\hline Item “Mental health” & 0.59 & 0.001 & \\
\hline Item "Life as a whole" & 0.54 & 0.003 & \\
\hline GQL & 0.55 & $<0.001$ & 1670 \\
\hline \multicolumn{4}{|l|}{ Instruments for important others } \\
\hline \multicolumn{4}{|l|}{ CBS-R } \\
\hline CBRS-R total sum & -0.17 & 0.232 & \multirow[t]{2}{*}{49} \\
\hline Item "Problem understanding what happens" & -0.28 & 0.048 & \\
\hline PGB & 0.32 & $<0.001$ & 744 \\
\hline \multicolumn{4}{|l|}{ Professional ratings instruments } \\
\hline \multicolumn{4}{|l|}{ BPRS } \\
\hline BPRS total sum & -0.41 & $<0.001$ & \multirow{5}{*}{124} \\
\hline Item "Anxiety" & -0.43 & $<0.001$ & \\
\hline Item "Depression" & -0.39 & $<0.001$ & \\
\hline Item "Hallucinations" & -0.33 & $<0.001$ & \\
\hline Item "Guilt" & -0.32 & $<0.001$ & \\
\hline \multicolumn{4}{|l|}{ SERS } \\
\hline SERS total index & -0.45 & $<0.001$ & \multirow{5}{*}{1670} \\
\hline Item “Tension/Inner unrest" & -0.48 & $<0.001$ & \\
\hline Item "Depression" & -0.47 & $<0.001$ & \\
\hline Item "Concentration difficulties" & -0.39 & $<0.001$ & \\
\hline Item "Asthenia/Lassitude/Increased fatigability" & -0.34 & $<0.001$ & \\
\hline GAF-S & 0.24 & $<0.001$ & 1670 \\
\hline
\end{tabular}

Significance level $p<0.001$.

perception of mental health as rated with the PGD was further supported by the fact that the only item in the comprehensive next-of-kin burden scale CBS-R that showed notable correlation $(r h o=-0.28)$, was an item about understanding the situation and correlation with the "important other's" global burden scale PGB $(r h o=0.32)$. The correlations with professional ratings on the BPRS and SERS scales provided some external validation to the patient construct of the PGD. Items concerned with anxiety and depression features were notably correlated to the PGD (rhos about $-0.4--0.5$ ). Also, the interpersonal aspect was supported (BPRS item "Guilt" $r h o=-0.32$ ). Interestingly, there may also be an indication that patients do also de facto consider psychosis specific elements, as there was notable correlation noted to the item "Hallucinations" in the BPRS, and there may also have been a connection to the negative symptoms of psychosis as SERS items for "Concentration Difficulties" and "Asthenia" showed correlations (rho -0.39 and -0.34 respectively". On the other hand the severity of symptoms did not seem to be similarly judged by patients and professionals as correlation to GAF-S was lower, rho $=0.24$. These findings were in support of views expressed by Lindström, Jedenius, and Levander (2009), who pointed out that: "patients appear to 
construct their appreciation of degree of illness differently than clinicians. Much of the feelings of being ill seems to be channeled via affective symptoms."

Regarding the importance of using patient subjective illness ratings in the clinical work Lindström et al. (2009) also suggest: "This may open an alternative way to communicate with (schizophrenia, authors' remark) patients about their illness. Rather than confronting them with respect to the psychotic symptoms ...... we should focus on their affective reaction to the actual situation". This view is very much coinciding with the intended construct of the PGD scale and its rationale for use, as was described in the Introduction: 'The PGD is intended to support problem identification in the mental health area together with the patient, and a following dialogue should clarify the precise nature of the problems that the patient experiences'. It was important that the question has an open character to facilitate that the patient's perception is expressed. The findings reported do support that the intended construct was achieved in a satisfactory way.

The successful use of clients' subjective ratings in alliance building to enhance recovery has also been suggested in terms of "Client-Directed Outcome-Informed (CDOI)" work (Duncan, Miller, Wampold, \& Hubble, 2010) The theory behind the Quality Star Concept fits well with the CDOI concept, relating the user and professional dimensions.

The study has weaknesses. The test-retest properties study reported in Results Section 4, was done in order to shed some light on the matter using the data available however, studies with a stricter design are necessary to verify the findings. Nevertheless, the present results were considered as a fairly robust indication that the test-retest properties were sufficiently reliable. The study was further hampered by the limited data available for some of validation instruments for instance regarding the concurrent validity study $(\mathrm{N}=27)$. Another weakness of the study was that participant background data was limited regarding for instance, sociodemographic data due to the naturalistic data sources, and we were thus not in the position to describe the possible influence of such external validation circumstances.

Also, as the PGD was constructed with the purpose to be a generic instrument regardless of diagnosis, the study was limited in clarifying these matters only for SMI persons in the schizophrenia spectrum. Although other diagnostic groups were also represented in the material, they were insufficient in numbers to allow detailed presentation. Further studies should also take in account the properties of PGD as a measure of change, which was not covered by this study. Finally, it should be pointed out that the question if VAS scales, like PGD, are suitable for obtaining correct categorical or numerical values for subjective phenomena is discussed, but the problem area was out of the scope for this paper.

In conclusion, it is suggested that the PGD in regard to serious mental ill persons with schizophrenia disorders was shown to have acceptable psychometric properties. It is deemed justified to use this easy to use instrument for screening perceived global distress in individual cases. Unsatisfactory level and change in PGD on repeated administration could be a signal to explore the problem closer by interview and/or specific instruments. On a group level, with aggregated data, it will be reasonable to foresee that the self-assessment Global Quality of Life Scale can be used in a similar fashion as for instance the
GAF scale, aiming at adding a user subjective view to the professional global severity rating.

\section{Acknowledgements}

Authors acknowledge the excellent technical assistance of Göran Eiman, RN, Ass. Head Psychiatric dept., Kungälv Hospital, Kungälv in preparing the database used. Our gratitude is also expressed to all users of the Quality Star method and their willingness to make their data available for this study. Our thanks goes also to Ms Carol Schultheis for her careful english language improvements suggest to us.

\section{References}

American Psychiatric Association (2000). Diagnostic and statistical manual of mental disorders (4th ed.). Washington, DC: American Psychiatric Press.

Andrews, G., \& Slade, T. (2001). Interpreting scores on the Kessler psychological distress scale (K10). The Australian and New Zealand Journal of Public Health, 25, 494-497. doi:10.1111/j.1467-842X.2001.tb00310.x

Bech, P. (1993). Rating scales for psychopathology, health status and quality of life. Berlin Heidelberg: Springer Verlag.

Bech, P., Malt, U. F., Dencker, S. J., Ahlfors, U. G., Elgen, K., Lewander, T. et al. (1993). Scales for assessment of diagnosis and severity of mental disorders. Acta Psychiatrica Scandinavica, 87, Supplement 372, 3-86.

Bergman, P. (2003). A validation study of the VAS scale Perceived distress in the quality star. Internal report the Quality star network. URL (last checked 2 March 2011)

http://www.kvalitetsstjarnan.se/Forskning\%20studier/SCL90\%20Ber gman\%20Ljungby\%20031217.pdf.

Bergmark, T., Durling, H., Boström, A., \& Wistedt, B. (1990). Family: Un underestimated but hard burdened resource in caringe. Läkartidningen, 87, 3287-3288.

Björkman, T., \& Svensson, B. (2005). Quality of life in people with severe mental illness. Reliability and validity of the Manchester Short Assessment of Quality of Life (MANSA). Nordic Journal of Psychiatry, 59, 302-306.

Derogatis, L. R. (1994). Symptom Checklist-90-R: Administration, scoring \& procedure manual for the revised version of the SCL-90. Minneapolis, MN: National Computer Systems.

Derogatis, L. R. (2000). Symptom Checklist-90-Revised. In A. J. Rush, M. M. First and D. Blacker (Eds.), Handbook of psychiatric measures (pp. 81-84). Washington, DC: American Psychiatric Association.

Derogatis, L. R., Lipman, R. S., \& Covi, L. (1973). SCL-90: An outpatient psychiatric rating scale-Preliminary report. Psychopharmacol Bulletin, 9, 13-28.

Duncan, B. L., Miller, S. D., Wampold, B. E., \& Hubble, M. A. (Eds.) (2010), The heart and soul of change-Delivering what works in therapy (2nd ed.). Washington DC: American Psychological Association.

Erdner, L., \& Eiman, G. (2003). Comparison studies between the quality star scare for next of kin and the CBS-R scale. Internal report the Quality star network. URL (last checked 2 March 2011) http://www.kvalitetsstjarnan.se/Forskning\%20studier/Erdner\%20Eim an\%20dec\%202003.pdf

Erdner, L., \& Ivarsson, B. (2002) The quality star-A tool for regular outcome monitoring. In M. London, (Ed.), ENTER Mental health (pp. 65-69). Cambridge: Print-Out.

Everitt, B. S., \& Wykes, T. (Eds.) (1999). A dictionary for statistics for psychologists. London: Arnold.

Fridell, M., Cesarec, Z., Johansson, M., \& Malling Andersen, S. (2002). SCL-90 Swedish norms, standardisation and validation of the 
symptom scale. Lund: Department of Psychology, Lund University \& National Board of Institutional Care (SiS).

GGG-Group of the Quality Star Network (2009). User's Instruments and manual. Present English version published by Karlstad University in cooperation with the Quality Star Network. Available though authors.

Goldberg, D. P., \& Williams, P. (1988). A user's guide to the general health questionnaire. Basingstoke: NFER-Nelson.

Harpham, T., Reichenheim, M., Oser, R., Thomas, E., Nasrmeen, H., Jaswal, S. et al. (2003). Measuring mental health in a cost-effective manner. Health Policy and Planning, 18, 344-49. doi:10.1093/heapol/czg041

Hjärthag, F., Helldin, L., \& Norlander, T. (2008). Family burden: Psychometric properties of the burden inventory for relatives to persons with psychotic disturbance. Psychological Reports, 103, 323-335

Holi, M. (2003). Assessment of psychiatric symptoms using the SCL-90. Doctoral Thesis, Helsinki: University of Helsinki.

Ivarsson, B., Andersson, J., Malmström, S., Carlsson, C., \& Johansson, B.-I. (2010). Normal population ratings on the Perceived Global Distress scale (PGD). Internal report for the Quality Star group and Evidens-FOU. URL (last ckecked 2 March 2011)

http://www.kvalitetsstjarnan.se/Forskning\%20studier/Normal\%20po pulation\%20ratings\%20PGD.pdf

Ivarsson, B., Erdner, L., \& Malm, U. (2006). The quality star-An algorithm for the evaluation of mental health services. ENMESH conference, Lund, 10 June 2006. URL (last checked 2 March 2011 http://www.kvalitetsstjarnan.se/Rapporter/THE\%20QUALITY\%20S TAR\%20060610.pdf

Ivarsson, B., \& Malm, U. (2007). Self-reported consumer satisfaction in mental health services: Validation of a self-rating version of the UKU-Consumer Satisfaction Rating Scale. Nordic Journal of Psychiatry, 61, 194-200. doi:10.1080/08039480701352488

Ivarsson, B., Malm, U., Lindström, L., \& Norlander, T. (2010). The self-assessment Global Quality of Life scale-Reliability and construct validity. International Journal of Psychiatry in Clinical Practice, 14, 287-297. doi:10.3109/13651501.2010.487217

Lindström, E., Jedenius, E., \& Levander, S. (2009). A symptom Self-rating Scale for Schizophrenia (4S): Psychometric properties, reliability and validity. Nordic Journal of Psychiatry, 63, 368-374. doi:10.1080/08039480902807298

Lingjaerde, O., Ahlfors, U. G., Bech, P., Dencker, S. J., \& Elgen, K. (1987). The UKU side effect rating scale. A new comprehensive rating scale for psychotropic drugs and cross-sectional study of side effects in neuroleptic-treated patients. Acta Psychiatrica Scandinavica, 76, Sup- plement 334, 1-100. doi:10.1111/j.1600-0447.1987.tb10566.x

O'Hare, T., Sherrer, M., Smith Connery, H., Thornton, J., LaButti, A., \& Emrick, K. (2003). Further validation of the psycho-social well-being scale (PSWS) with community clients. Community Mental Health Journal, 39, 115-129. doi:10.1023/A:1022658503553

Patterson, D. A., \& Lee, M. S. (1995). Field trial of the Global assessment of functioning scale-modified. The American Journal of Psychiatry, 152, 1386-1388.

Pedersen, G., Hagtvet, K. A., \& Karterud, S. (2007). Generalizability studies of the global assessment of functioning - Split version. Comprehensive Psychiatry, 48, 88-94. doi:10.1016/j.comppsych.2006.03.008

Priebe, S., Huxley, P., Knight, S., \& Evans, S. (1999) Application of the manchester short assessment of quality of life (MANSA). International Journal of Social Psychiatry, 45, 7-12. doi:10.1177/002076409904500102

Skantze, K., \& Malm, U. (1994). A new approach to facilitation of working alliances based on patients' quality of life goals. Nordic Journal of Psychiatry, 48, 37-55. doi:10.3109/08039489409078125

Skantze, K., Malm, U., Dencker, S. J., May, P. R., \& Corrigan, P. (1992). Comparison of quality of life with standard of living in schizophrenic out-patients. The British Journal of Psychiatry, 161, 797-801. doi:10.1192/bjp.161.6.797

Söderberg, P. (2007). The Episode project. Treatment effects, Psychiatric ambulatory care 2006. Report for the NYSAM psychiatric development group. Säter: Psychiatric Development unit, Dalarna County. URL (last checked 2 March 2011)

http://www.ltdalarna.se/upload/1493/Episodprojektet\%20original\%2 02006\%20070402.pdf

Söderberg, P., \& Tungström, S. (2007). Outcome in psychiatric outpatient services. Reliability, validity and outcome based on routine assessments with the GAF scale. PhD Thesis, Umeå: Umeå University.

Ventura, M. A., Lukoff, D., Nuechterlein, K. H., Liberman, R. P. Green, M. F., \& Sahner, A. (1993). Manual for the expanded brief psychiatric rating scale. International Journal of Methods in Psychiatric Research, 3, 221-244.

Ventura, M. A., Lukoff, D., Nuechterlein, K. H., Subotnik, K., \& Gilbert, E. (1995). Symtom dimensions in recent-onset schizophrenia: The 24-item expanded BPRS. The 5th International Congress on Schizophrenia Research, 15, 22

Yamauchi, K., Ono, Y., Baba, K., \& Ikegami, N. (2001). The actual process of rating the global assessment of functioning scale. Comprehensive Psychiatry, 42, 403-409.

doi:10.1053/comp.2001.26268 